\title{
A dynamic view of proton-coupled electron transfer in photocatalytic water splitting
}

\author{
Adriano Monti, Jessica M. de Ruiter, Huub J. M. de Groot, Francesco Buda*
}

Leiden University, Leiden Institute of Chemistry, Einsteinweg 55, 2300 RA, Leiden, The

Netherlands

\begin{abstract}
Solar-driven water splitting is a key reaction step in a photoelectrochemical cell for solar fuel production. We propose a photoanode in which a $\mathrm{TiO}_{2}$ substrate is functionalized with a supramolecular complex consisting of a fully organic naphthalene-diimide (NDI) dye covalently bound to a mononuclear Ru-based water oxidation catalyst. By performing abinitio Molecular Dynamics simulations we elucidate microscopic details of water oxidation at the photoanode induced by visible light absorption. The fast photoinduced electron injection from the NDI into the semiconductor provides the driving force for the activation of the Ru catalyst. The proton-coupled electron transfer nature of this catalytic reaction path is unveiled through the explicit description of the water environment, which is essential to determine the proton diffusion channel and the free energy change along the reaction. The mechanistic insight into the photocatalytic processes obtained with our computational strategy can facilitate the design of new and efficient photoelectrochemical devices.
\end{abstract}




\section{INTRODUCTION}

Direct conversion of solar energy into storable chemical fuel is a promising strategy on the path towards sustainable energy sources ${ }^{1,2}$. Natural systems perform this task by converting water molecules into $\mathrm{O}_{2}$ and high-energy-density molecular compounds. ${ }^{3,4}$ They apply molecular machineries, which are complex, but without redundancy in the biological context of the membrane and the cell. The design of artificial solar energy conversion devices ${ }^{5}$ aims at applying essential fundamental principles governing natural photosynthesis, while aiming for dedicated solar to fuel conversions, which allows using a much simpler structure. ${ }^{6-12}$

A photoelectrochemical solar fuel cell device combines the functions of light harvesting, charge separation and catalysis. ${ }^{13-15}$ In the last decade several systems have been proposed employing either metal oxide nanoparticles ${ }^{8,16-24}$ or molecular complexes ${ }^{8,25-28}$ as water oxidation catalyst (WOC). Furthermore, the coupling between the WOC, the chromophore and an electron accepting semiconductor into a photoanode has been achieved through co-absorption of both the catalyst and the chromophore ${ }^{16,29-}$ 32 or through dye-WOC supramolecular complexes. ${ }^{33-36}$

Acquiring a fundamental understanding of the electron transfer processes and catalytic water oxidation mechanism following light excitation of the photoanode is essential for the design and the optimization of solar fuel cells. However, this is a challenging task mainly because of the different time scales of the processes occurring upon photoexcitation. In this work we introduce a computational strategy to tackle this problem by bridging the description of the electron injection and catalytic water oxidation mechanisms. This approach is applied to photoanode $\mathbf{1}$ (see Scheme 1), representing a computational design option for visible light water splitting.

In system $\mathbf{1}$ a Ru-based WOC is covalently bound to an organic chromophore that is directly anchored to a $\mathrm{TiO}_{2}$ semiconductor surface. $\mathrm{TiO}_{2}$ is by far the most common choice for the semiconductor to be used in a dye-sensitized photoelectrochemical cell $(D S-P E C)^{8}$, due to its excellent stability in combination with a high density of states of its conduction band, which allows for rapid electron injection rates ${ }^{37-39}$. The WOC considered in this system is the mono Ru-complex $\left[(\mathrm{cy}) \mathrm{Ru}^{\mathrm{II}} \mathrm{bpy}\left(\mathrm{H}_{2} \mathrm{O}\right)\right]^{2+}$. This catalyst has been already theoretically and experimentally investigated in the literature, and its catalytic cycle has been suggested to proceed through four consecutive proton-coupled electron transfer (PCET) steps ${ }^{40,41}$.

The molecular chromophore 2,6-diethoxy-1,4,5,8-diimidenaphthalene $\left(\mathrm{NDI}_{1}\right)$ has been already employed as visible light antenna for solar energy conversion applications. ${ }^{42,43}$ The family of NDI chromophores has found wide applications in dye-sensitized devices since their optical properties can be easily tuned over a wide light-spectrum. ${ }^{44}$ 
Furthermore, they allow the construction of $n / p$-supramolecular heterojunctions presenting antiparallel gradients in electron and holes channels to achieve photoinduced long-distance charge separation and reduce charge recombination. ${ }^{45-48}$
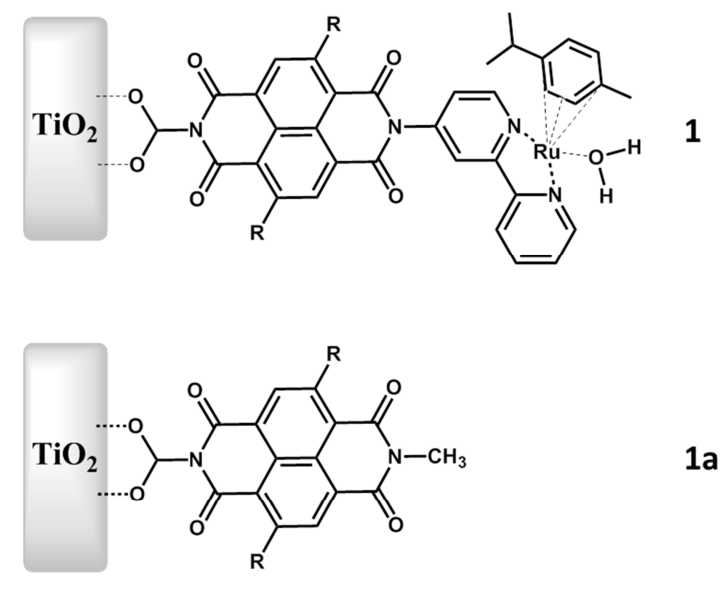

$1 a$

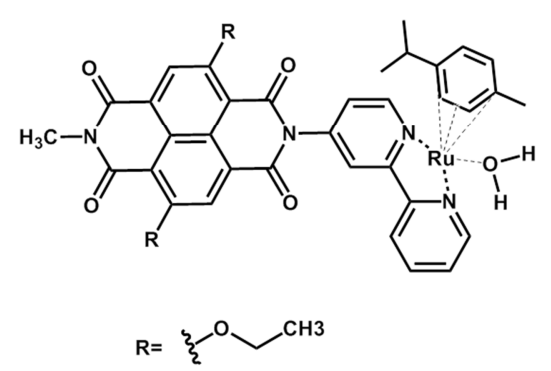

1b

Scheme 1. Schematic representation of the proposed photoanode (1) including the acceptorsemiconductor $\left(\mathrm{TiO}_{2}\right)$, the molecular chromophore $\mathrm{NDI}_{1}$, and the Ru-based water oxidation catalyst; (1a) chromophore-semiconductor subsystem employed for the photoinduced electron injection simulation; (1b) chromophore-catalyst subsystem used in the simulation of the first water oxidation catalytic step. $\mathrm{R}$ represents the diethoxy moiety functionalizing the chromophore naphthalene core.

The chosen NDI ${ }_{1}$ antenna absorbs at wavelengths of $\sim 470 \mathrm{~nm}$ and is characterized by ground and excited states oxidation potentials of $\sim-6.16 \mathrm{eV}^{43}$ (vs. vacuum) and $\sim-3.8$ $\mathrm{eV}^{43}$ (vs. vacuum), respectively, which provide a good match with the semiconductor band edge and the catalyst oxidation potential of $\sim-6.2 \mathrm{eV} v s$. vacuum. ${ }^{41}$ These properties allow the $\mathrm{NDI}_{1}$ to undergo photoinduced electron injection into the $\mathrm{TiO}_{2}$ conduction band ( $\sim 4 \mathrm{eV}$ vs. vacuum) with little energy loss. At the same time, due to its ground state oxidation potential, the $\mathrm{NDI}_{1}$ photoexcitation is able to trigger the catalytic activity of the $\left[(\mathrm{cy}) \mathrm{Ru}^{\mathrm{II}} \text { bpy }\left(\mathrm{H}_{2} \mathrm{O}\right)\right]^{2+}$ WOC. ${ }^{41}$

We show that the photoexcitation of system $\mathbf{1}$ induces the heterogeneous electron injection and the first PCET step for catalytic water oxidation. These two strongly correlated processes are found to proceed on different time scales. The ultrafast nature of the electron injection between $\mathrm{NDI}_{1}$ and $\mathrm{TiO}_{2}$ in system $\mathbf{1 a}$ (Scheme 1) is found 
through nonadiabatic dynamics. On the other hand the dynamical description of the first catalytic water splitting step is obtained with adiabatic ab initio constrained MD simulations performed for the oxidized antenna-catalyst model 1b (Scheme 1). The use of an explicit solvent highlights the active role of the water environment in defining the water oxidation reaction path ${ }^{49-52}$ and its PCET character. The free energy barrier and the thermodynamic driving force are characterized along the reaction path. The computational strategy applied in this work represents an invaluable tool to describe a wide range of photo-catalytic reactions and can provide guidelines for the development of solar energy conversion devices.

\section{COMPUTATIONAL DETAILS}

Quantum-classical simulation of model 1a. The chromophore of model $\mathbf{1 a}$ is prepared by functionalizing the $\mathrm{NDI}_{1}$ molecule with a carboxylic acid anchoring group on one of the amide moieties. The geometry of the chromophore is then optimized in vacuum with the ADF software package $\mathrm{53,54}^{\mathbf{5}}$ at the density functional theory (DFT) level employing the exchange-correlation functional $\mathrm{OPBE}^{55}$ and the TZP Slater type basis set.

The optimized chromophore is attached to the $\mathrm{TiO}_{2}$ surface through the carboxylate bridge in a bidentate anchoring mode to form model 1a shown in Scheme 1.

The electronic properties of this model are described by means of a tight-binding Hamiltonian based on the extended Hückel $(\mathrm{EH})$ theory ${ }^{56,57}$. For the optimization of the $\mathrm{NDI}_{1}$ atomic parameters, the experimental ground-state $(-6.16 \mathrm{eV}$ vs. vacuum) and excited state ( $-3.82 \mathrm{eV}$ vs. vacuum) redox potentials ${ }^{43}$ are taken as target values for the HOMO and LUMO energies of the chromophore. For the atoms of the semiconductor slab, standard $\mathrm{EH}$ parameters ${ }^{58}$ are employed without any further modification. An exhaustive description of the parameterization procedure can be found elsewhere ${ }^{59,60}$.

The time evolution of the electronic wavepacket is performed through the atomic

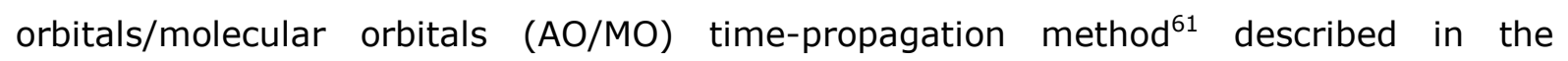
Supporting Information and in Scheme SI1. This methodology has been already applied successfully for the description of nonadiabatic heterogeneous electron transfer processes $^{62,63}$. In this method the wavepacket is evolved under the influence of an underlying nuclear trajectory ${ }^{64}$. This ground state nuclear trajectory is calculated for model 1a through ab initio Molecular Dynamics using the Car-Parrinello MD (CPMD) $\operatorname{code}^{65}$. The MD simulations are performed in vacuum using the pseudopotentials of references ${ }^{66,67}$ with a plane wave cut-off of 70 Rydberg and the OPBE $^{55}$ exchange correlation functional. Applying the Nosé-Hoover thermostat, the whole 1a model is brought to a temperature of $300 \mathrm{~K}$ and allowed to equilibrate for $\sim 2 \mathrm{ps}$ using a time step 
of $\delta t=0.1 \mathrm{fs}$. The second half of this nuclear trajectory is used for the electronic wavepacket propagation, which is carried out using the same time step of the CPMD simulation.

To model the $\mathrm{TiO}_{2}$ surface, an orthorhombic supercell with lattice parameters $a=10.239$ $\AA, b=15.137 \AA$ and $c=40 \AA$ is used, together with periodic boundary conditions. The cell contains a two layers anatase slab $\left(\mathrm{TiO}_{2}\right)_{32}$ functionalized with the $\mathrm{NDI}_{1}$ chromophore.

\section{DFT electronic and optical characterization of model 1b}

Using the ADF software package, the ground state geometry of system $\mathbf{1 b}$ is initially optimized at the DFT level using the OPBE exchange-correlation functional ${ }^{55}$ and the TZP basis set. The optimization is performed in an aqueous environment simulated with the continuous solvation model (COSMO ${ }^{68,69}$ ) implemented in ADF.

The OPBE exchange-correlation functional has been shown to provide accurate descriptions of transition metals complexes ${ }^{70-72}$, among which the $\left[(c y) \mathrm{Ru}^{\mathrm{II}} b p y\left(\mathrm{H}_{2} \mathrm{O}\right)\right]^{2+}$ catalyst $^{40}$ used in system 1b. In particular, the oxidation potential of the $\left[(\mathrm{cy}) \mathrm{Ru}^{\mathrm{II}} \mathrm{bpy}\left(\mathrm{H}_{2} \mathrm{O}\right)\right]^{2+}$ catalyst computed with OPBE is found to be $-6.2 \mathrm{eV}$, in good agreement with the experimental data. ${ }^{41}$ The same computational setting closely reproduces the experimental ground state oxidation potential for $\operatorname{NDI}_{1}(-6.16 \mathrm{eV})^{43}$ within the 1b complex, giving a value of $-6.05 \mathrm{eV}$ vs. vacuum calculated using the $\triangle \mathrm{SCF}$ approach.

TD-DFT calculations for the absorption spectrum of system $\mathbf{1 b}$ are performed using the ADF software package at the $\mathrm{B} 3 \mathrm{LYP}^{73} / \mathrm{TZP}$ level of theory. The aqueous solution is described within the COSMO model. The choice of the exchange correlation functional is justified by the results presented in reference ${ }^{42}$, where B3LYP has been shown to accurately reproduce the experimental optical properties of the $\mathrm{NDI}_{1}$ molecule.

\section{Constrained $a b$ initio MD of model 1b}

To investigate whether the photoinduced oxidation of the dyad can initiate the catalytic process of water oxidation, $a b$ initio MD simulations are performed for the singly oxidized form of the catalyst-antenna complex $\mathbf{1 b}^{+}$with the CPMD program. To obtain a realistic description of the PCET reaction, the solvent is explicitly introduced in the simulation $40,51,74$. An orthorhombic box of dimensions $25 \times 17.6 \times 14.5 \AA^{3}$ is used, containing the $\mathbf{1 b}$ solute and 162 water molecules. Both the solvent and the solute molecules are treated at the same quantum-mechanical level employing the OPBE exchange correlation functional and the dispersion-corrected atom-centered pseudopotential of reference ${ }^{66}$. Periodic boundary conditions are applied together with a plane wave cut-off of 70 Rydberg. The time step in the $a b$ initio MD simulations is $\delta t=0.1 \mathrm{fs}$. The solvated system has been equilibrated with the following procedure: 
First the water solvent is equilibrated at room temperature for about 1 ns using the TIP3P model implemented in the CHARMM force field, while the WOC-dye molecular complex is kept fixed. Then the whole system, including the complex $\mathbf{1 b}$ in the nonoxidized state, is further evolved for about 100 fs using the CPMD code. Finally, one electron is removed from the simulation box and the oxidized state is evolved for $\sim 3 \mathrm{ps}$ at room temperature by applying the Nosé-Hoover thermostat.

To sample regions of the phase space that would be rarely visited during a standard MD simulation, such as transition states, a rare event simulation technique is required. Specifically, we apply the so called Blue-Moon approach, consisting in forcing the system to explore the region of interest by constraining a given reaction coordinate during the MD simulations ${ }^{75-77}$. The distance between one of the protons of the water molecule coordinated to the $\mathrm{Ru}$ atom, and the oxygen of one of the adjacent solvating water molecules is chosen as the constrained reaction coordinate. Five points within the range 1.4-0.98 $\AA$ are considered for this coordinate. For every value of the constraint, the system is evolved until the associated average Lagrange multiplier, corresponding to the gradient of the free energy associated to the reaction coordinate, is equilibrated. ${ }^{77}$ The free energy variation for the whole process is then obtained via thermodynamic integration.

\section{RESULTS AND DISCUSSION}

The results are organized as follows: first, the optical properties of the $\left[(\mathrm{cy}) \mathrm{Ru}^{\mathrm{II}} \mathrm{bpy}\left(\mathrm{H}_{2} \mathrm{O}\right)\right]^{2+}-\mathrm{NDI}_{1}$ dyad $\mathbf{1} \mathbf{b}$ are presented. The study of the photoinduced electron injection for model $\mathbf{1} \mathbf{a}$ is presented in the next section. Finally, the mechanism of the first water oxidation step is investigated using model $\mathbf{1} \mathbf{b}$.

\section{TD-DFT characterization of the electronic excitations of the dye-catalyst complex and Molecular Orbitals localization}

In order to evaluate the optical properties of the $\mathrm{NDI}_{1}$ antenna coupled to the water oxidation catalyst $\left[(\mathrm{cy}) \mathrm{Ru}^{\mathrm{II}} \mathrm{bpy}\left(\mathrm{H}_{2} \mathrm{O}\right)\right]^{2+}$, a time-dependent DFT calculation is performed for the dyad $\mathbf{1 b}$ in a water environment described through a continuous solvation model. 


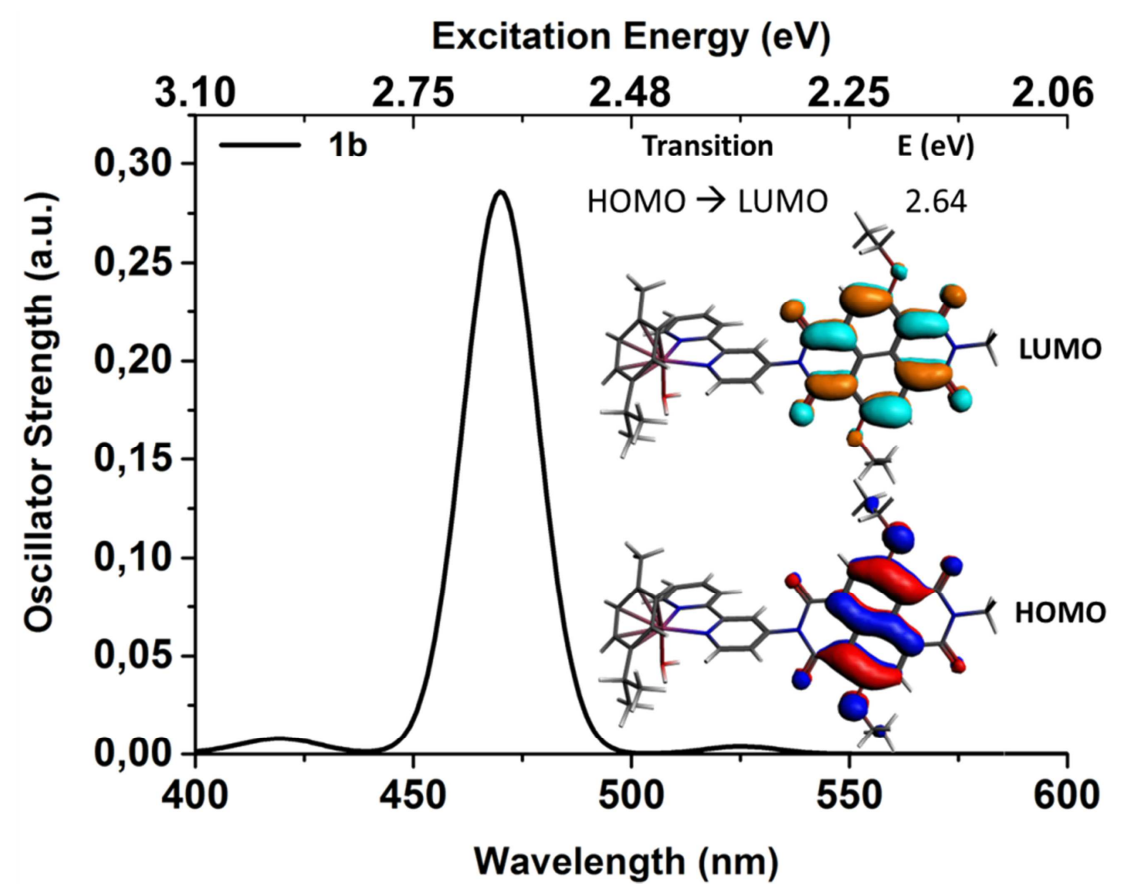

Figure 1. Optical absorption spectrum of system 1b, computed at the B3LYP/TZP level of theory. The water solvent is included through the continuum solvation model (COSMO) as implemented in the ADF software package ${ }^{53}$. The oscillator strength is in arbitrary units (a.u.). The inset shows the localization of the HOMO and LUMO, which are the only orbitals involved in the optical transition at $2.64 \mathrm{eV}$.

The results in Figure 1 show the presence of a single dominant peak within the visible light spectral range at $\sim 470 \mathrm{~nm}$. The analysis of this electronic excitation reveals that it is associated with the HOMO to LUMO transition, localized on the chromophore subunit (see inset Figure 1).

The calculated optical absorption energy compares well with the experimental data and computational results for the monomer $\mathrm{NDI}_{1}$ reported in references ${ }^{44}$ and ${ }^{59}$. This result provides evidence that the visible-light photoexcitation of the dyad does not involve the Ru-catalyst subunit, which consequently is not expected to play a significant role in the formation of the sensitizer excitonic state. This justifies investigating the process of photoinduced electron injection into the semiconductor without explicitly including the catalyst in the definition of the electron donor (see model $\mathbf{1 a}$ ).

\section{Photoinduced electron injection dynamics in the $\mathrm{NDI}_{1}-\mathrm{TiO}_{2}$ model 1a}

The photoinduced electron injection dynamics is performed using the tight-binding extended Hückel approach. The computed density of states (DOS) for model 1a obtained with the optimized Hückel parameters (see Figure SI1 in the Supporting Information) shows that the LUMO energy of the chromophore falls near the conduction band edge of $\mathrm{TiO}_{2}$. This feature of the electronic structure of model $\mathbf{1 a}$ should allow for photoinduced electron injection while limiting to a minimum the loss of the potential induced by the 
photoexcitation in the form of heat.

Based on the TD-DFT results, the instantaneous photoexcitation of $\mathrm{NDI}_{1}$ is simulated by promoting an electron from the HOMO to the LUMO of the chromophore. This initial wavepacket state is reported in Figure $\mathbf{2}$ (inset (a)).

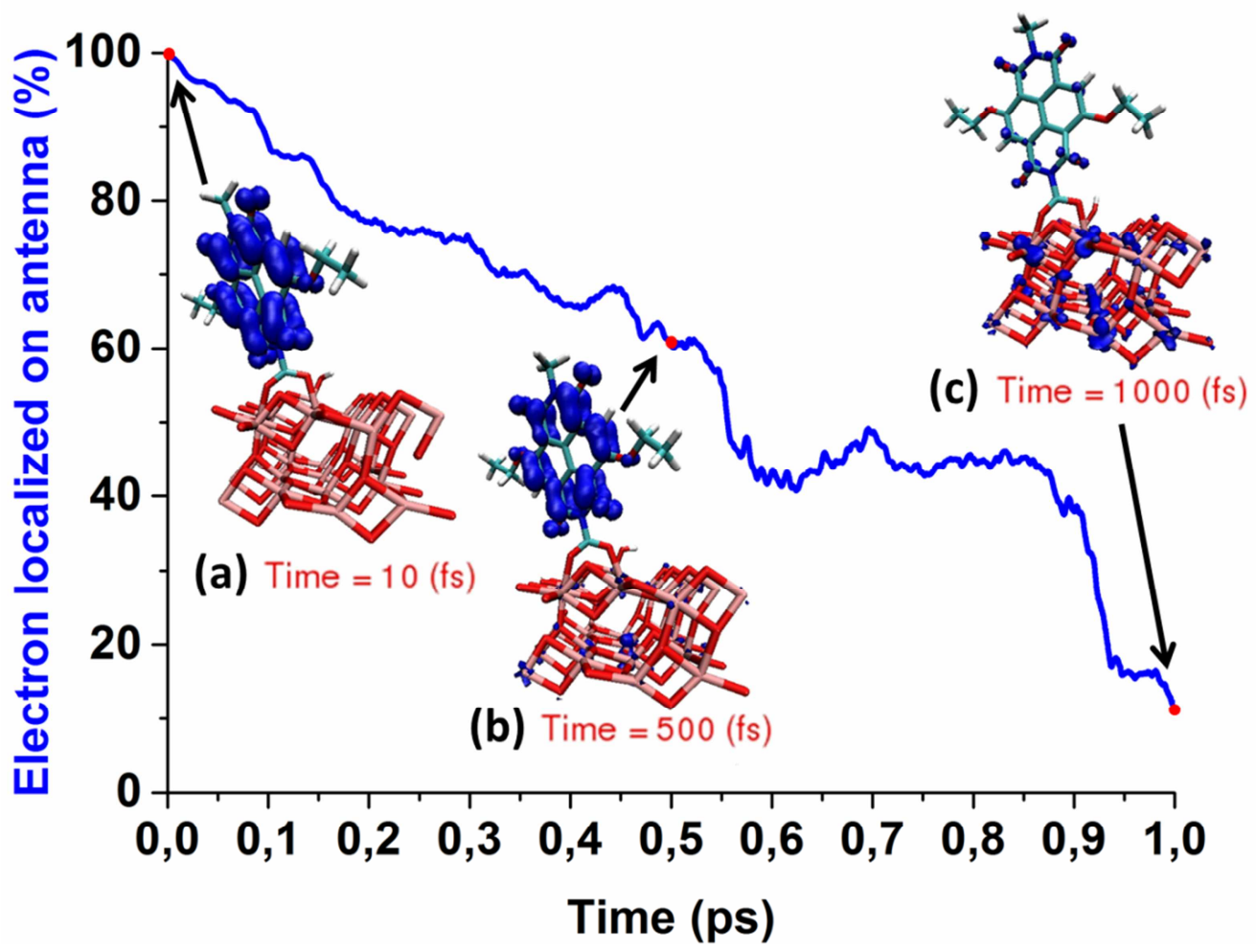

Figure 2. Electron injection profile obtained through the time-dependent population analysis of the wavepacket projected only over the $\mathrm{NDI}_{1}$ antenna (blue line). The insets show the distribution of the total wavepacket after initialization ( $a$ ), and along the MD trajectory (b and c).

The results of the electron quantum dynamics coupled to the nuclear motion show that the electron injection occurs in about 1 ps. Inset (c) in Figure 2, shows that at the end of the simulation the wavepacket is almost completely localized at the $\mathrm{TiO}_{2}$ surface. Overall, these results provide clear converging evidence that system $\mathbf{1}$ can undergo electron injection upon photoexcitation of its $\mathrm{NDI}_{1}$ antenna unit.

In general, water oxidation catalysis is known to occur over time scales orders of magnitude larger than the picosecond electron injection process observed here for system $\mathbf{1} \mathbf{a}^{4,78,79}$. Therefore, it is reasonable to assume that, upon photoexcitation, the electron injection will occur before the catalytic water oxidation can take place, leaving the antenna-catalyst dyad in an oxidized state.

An open issue in the context of dye-sensitized devices is the need to slow down the charge recombination process from the semiconductor into the oxidized sensitizer, since this quenching process can severely limit the quantum yield of the DS-PEC device. The quantum dynamics for the electron injection has been then extended for a further 
picosecond during which no sign of electron recombination has been observed, indicating a stable charge separated state on this time scale. The potential problem of charge recombination can be also alleviated by inserting appropriate molecular bridge units with rectifying properties between the dye and the semiconductor ${ }^{16,59,80,81}$ or by engineering $\mathrm{n} / \mathrm{p}$-supramolecular heterojunctions. ${ }^{45-48}$ We will no further address this point in this work and assume a long-lived oxidized state.

In the next section, it is shown that this oxidized state of the antenna-catalyst dyad (1b) is able to drive the first catalytic step of water oxidation.

\section{First PCET catalytic water oxidation step}

$A b$ initio molecular dynamics simulations are performed for the oxidized dyad model 1b in an explicit water solvent. Since we are interested in describing the proton-coupled electron transfer step, it is essential to treat the water molecules at the same DFT quantum-mechanical level of the solute. Proton diffusion in liquid water is a complex process that involves covalent bond breaking and formation within the hydrogen bonding network ${ }^{82-86}$. This process is commonly described within the framework of the Grotthuss mechanism ${ }^{87}$.

After equilibration of the dyad in its initial stable intermediate $\left[(\mathrm{cy}) \mathrm{Ru}^{\mathrm{II}} \mathrm{bpy}\left(\mathrm{H}_{2} \mathrm{O}\right)\right]^{2+}-\mathrm{NDI}_{1}$, the instantaneous photoexcitation and ultrafast electron injection are mimicked by removing an electron from the simulation box, creating the oxidized intermediate $\left[(\mathrm{cy}) \mathrm{Ru}^{\mathrm{II}} \text { bpy }\left(\mathrm{H}_{2} \mathrm{O}\right)\right]^{2+}-\mathrm{NDI}_{1}{ }^{+}$. Therefore, we can monitor the localization of the photoinduced hole along the $a b$ initio MD simulation by tracing the spin density of the unpaired electron. It is observed that at the beginning of the simulation $(t=0)$ the hole is localized on the $\mathrm{NDI}_{1}$.

The oxidized system is then equilibrated at room temperature for about 3 ps (see Figure 3). The analysis of this MD trajectory shows that the water molecule w1, coordinated to the $\mathrm{Ru}$ center, forms strong hydrogen bonds with nearby solvent molecules. In Figure 3, the $\mathrm{H}(\mathrm{w} 1)-\mathrm{O}(\mathrm{w} 1)$ (black line) and the $\mathrm{H}(\mathrm{w} 1) \cdots \mathrm{O}(\mathrm{w} 2)$ (blue line) distances along the MD trajectory are reported. Spontaneous attempts of proton transfer from $w 1$ to the neighbor water molecule w2 (see inset in Figure 3) are observed after about 1.6 ps and 1.9 ps, when the $\mathrm{H}(\mathrm{w} 1)-\mathrm{O}(\mathrm{w} 1)$ and $\mathrm{H}(\mathrm{w} 1) \cdots \mathrm{O}(\mathrm{w} 2)$ distances are almost equal. During these attempts, the $\mathrm{H}(\mathrm{w} 1) \cdots \mathrm{O}(\mathrm{w} 2)$ distance is reduced from an average value of $\sim 1.7 \AA$ to $\sim 1.2 \AA$, while the $\mathrm{H}(\mathrm{w} 1)-\mathrm{O}(\mathrm{w} 1)$ distance increases from $\sim 0.96 \AA$ to again a value of $\sim 1.2 \AA$. When the two distances are almost equivalent, the $\mathrm{H}(\mathrm{w} 1)$ proton can be considered as shared between the two water molecules $\mathrm{w} 1$ and $\mathrm{w} 2$. 


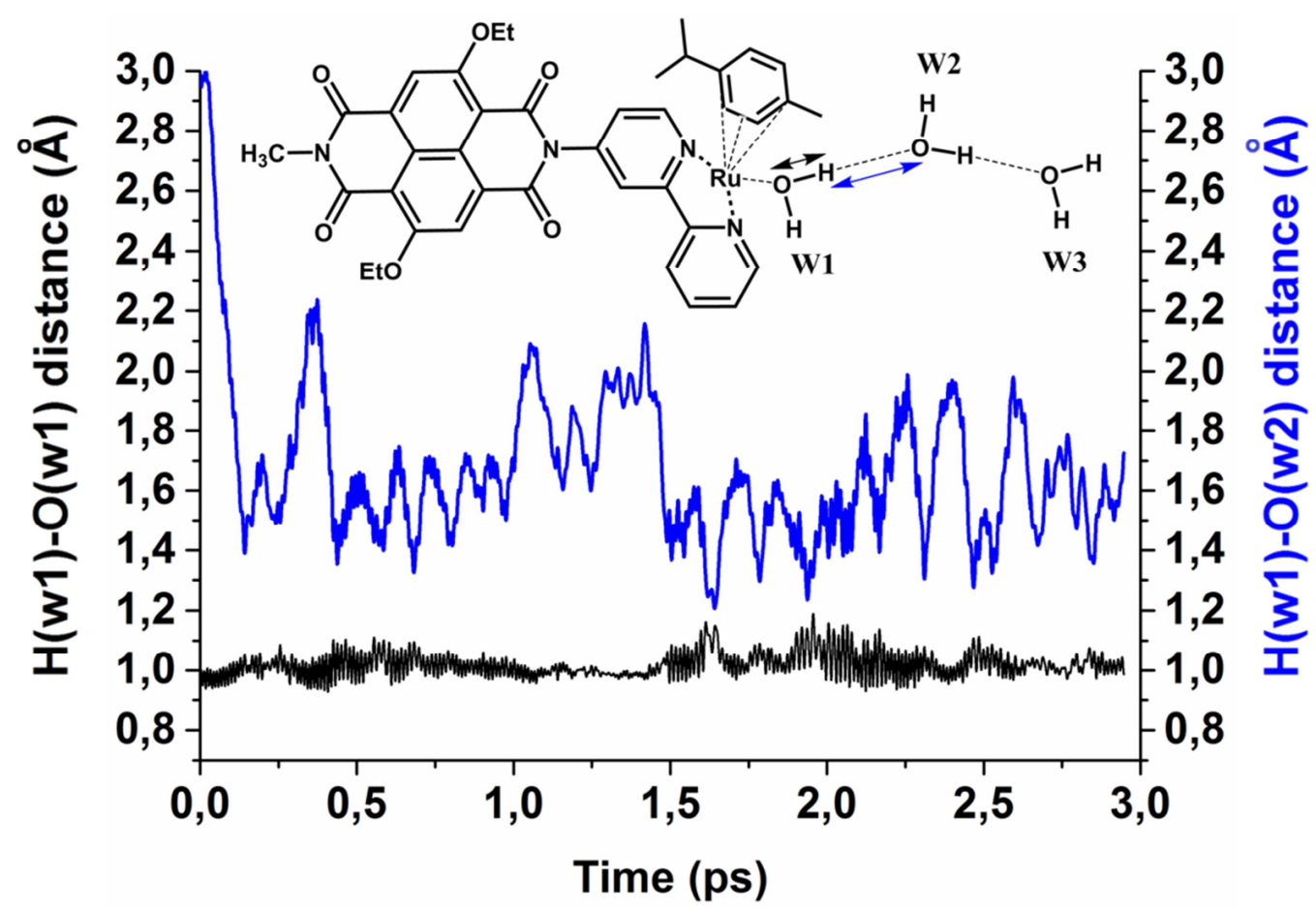

Figure 3. Time evolution of the geometrical parameters $H(w 1) \cdots O(w 2)$ (blue line) and $\mathrm{H}(\mathrm{w} 1)-\mathrm{O}(\mathrm{w} 1)$ (black line) along the unconstrained $a b$ initio MD for the explicitly solvated $\left[(\mathrm{cy}) \mathrm{Ru}^{\mathrm{II}} \mathrm{bpy}\left(\mathrm{H}_{2} \mathrm{O}\right)\right]^{2+}-\mathrm{NDI}_{1}{ }^{+}$complex. The inset schematically shows the dyad structure together with a few water molecules along the hydrogen bonding network.

These events represent the initial attempts of the system to spontaneously undergo the first PCET step in the water oxidation catalytic cycle and shift the redox equilibrium to the right in equation (i):

$$
\left[(\mathrm{cy}) \mathrm{Ru}^{\mathrm{II}} \mathrm{bpy}\left(\mathrm{H}_{2} \mathrm{O}\right)\right]^{2+}-\mathrm{NDI}_{1}^{+}+2 \mathrm{H}_{2} \mathrm{O} \leftrightarrow\left[(\mathrm{cy}) \mathrm{Ru}^{\mathrm{III}} \mathrm{bpy}(\mathrm{HO})\right]^{2+}-\mathrm{NDI}_{1}+\mathrm{H}_{5} \mathrm{O}_{2}^{+}
$$

In this catalytic step, an electron is transferred from the Ru-catalyst to the $\mathrm{NDI}_{1}$ antenna, and at the same time, a proton is released into the solvent. In equation (i) the water solvent is arbitrarily represented by only two water molecules. Given the large number of degrees of freedom involved in the solvent reorganization associated with the formation of the $\left[(\mathrm{cy}) \mathrm{Ru}^{\mathrm{III}} \mathrm{bpy}(\mathrm{HO})\right]^{2+}-\mathrm{NDI}_{1}$ intermediate, the reaction (i) may require a time frame longer than the few ps investigated in our ab initio MD simulations. To accelerate the process, we perform a series of constrained MD simulations where the $\mathrm{H}(\mathrm{w} 1) \cdots \mathrm{O}(\mathrm{w} 2)$ distance is progressively decreased from $1.4 \AA$ to $0.98 \AA$ (dashed blue lines in Figure 4). The choice of the $\mathrm{H}(\mathrm{w} 1) \cdots \mathrm{O}(\mathrm{w} 2)$ distance as the reaction coordinate is justified by the observations reported for the unconstrained $a b$ initio MD simulation (see Figure 3). At the end of the $0.98 \AA$ simulation, an unconstrained MD trajectory is performed to test the stability of the obtained first intermediate in the catalytic cycle. 


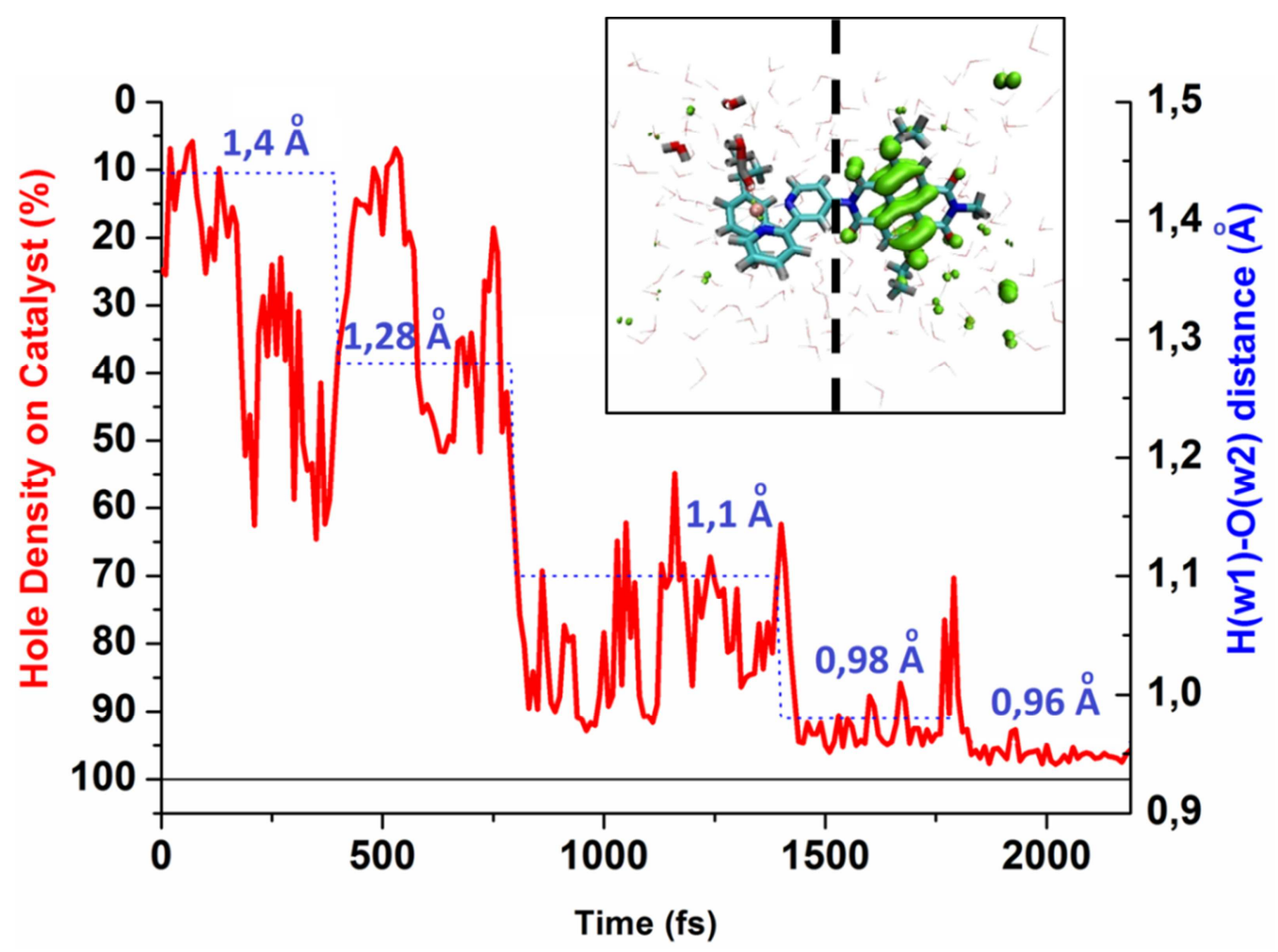

Figure 4. Red line: Percentage of the hole density obtained by integrating the spin density in the half of the simulation box including the catalyst (left hand side of the dashed black line in the inset). Blue dotted line: value of the constrained $\mathrm{H}(\mathrm{w} 1) \cdots \mathrm{O}(\mathrm{w} 2)$ reaction coordinate applied in the MD simulations. The results reported after 1800 fs correspond to an unconstrained simulation of the first catalytic intermediate in which the average $\mathrm{H}(\mathrm{w} 1)-\mathrm{O}(\mathrm{w} 2)$ distance is $0.96 \AA$. The inset shows a snapshot from the beginning of the trajectory corresponding to a constraint value of $1.4 \AA$, where the spin density is almost completely localized over the $\mathrm{NDI}_{1}$.

The results of the different constrained MD trajectories are collected in Figure 4, which shows the hole density percentage localized on the catalyst (red line). The hole density fluctuations along the trajectory provide evidence for strong coupling between the variations of the $\mathrm{H}(\mathrm{w} 1) \cdots \mathrm{O}(\mathrm{w} 2)$ distance and the electron transfer between $\mathrm{NDI}_{1}{ }^{+}$ and $\left[(\mathrm{cy}) \mathrm{Ru}^{\mathrm{II}} \mathrm{bpy}\left(\mathrm{H}_{2} \mathrm{O}\right)\right]^{2+}$.

For constrained distances between $1.4 \AA$ and $1.28 \AA$, the hole density localized on the catalyst fluctuates around an average of $\sim 35 \%$ of an electronic equivalent. This behaviour is observed also during the 3 ps unconstrained MD (Figure 3). It can be rationalized based on the similar oxidation potentials for $\mathrm{NDI}_{1}$ and the Ru-catalyst and on the strong electronic coupling between reactant and product states. The shortening of the $\mathrm{H}(\mathrm{w} 1) \cdots \mathrm{O}(\mathrm{w} 2)$ distance to $1.1 \AA$ induces a stronger localization of $\sim 80 \%$ of the hole density on the catalyst. A further displacement of the $H(w 1)$ proton towards the water molecule $\mathrm{w} 2$ reduces the charge fluctuations, leading to the $\left[(\mathrm{cy}) \mathrm{Ru}^{\mathrm{III}} \mathrm{bpy}(\mathrm{HO})\right]^{2+}$ catalytic 
intermediate. The stability of this product state is confirmed by removing the constraint: the unconstrained MD results after 1800 fs show that the newly formed $\mathrm{H}(\mathrm{w} 1)-\mathrm{O}(\mathrm{w} 2)$ bond length oscillates around an equilibrium distance of $0.96 \AA$. At the same time, the spin density remains localized on the catalyst, consistent with the doublet state of the $\mathrm{Ru}^{\mathrm{III}}$ intermediate of the isolated catalyst, reported for comparison in Figure SI2. This intermediate is characterized by a spin density mostly localized on the metal center and partially on the $\mathrm{OH}$ ligand.

Figure 5 shows how the spin density gradually moves from the $\mathrm{NDI}_{1}^{+}$to the $\mathrm{Ru}^{\mathrm{III}}$ catalyst along the trajectory, in response to the proton transfer. Since the ability of generalized gradient approximation (GGA) functionals to properly describe the localization of spin density has been questioned in the literature, ${ }^{88}$ we have performed an additional test with the hybrid B3LYP functional, showing that the spin density is virtually identical to that obtained with the OPBE functional (see Figure SI3).
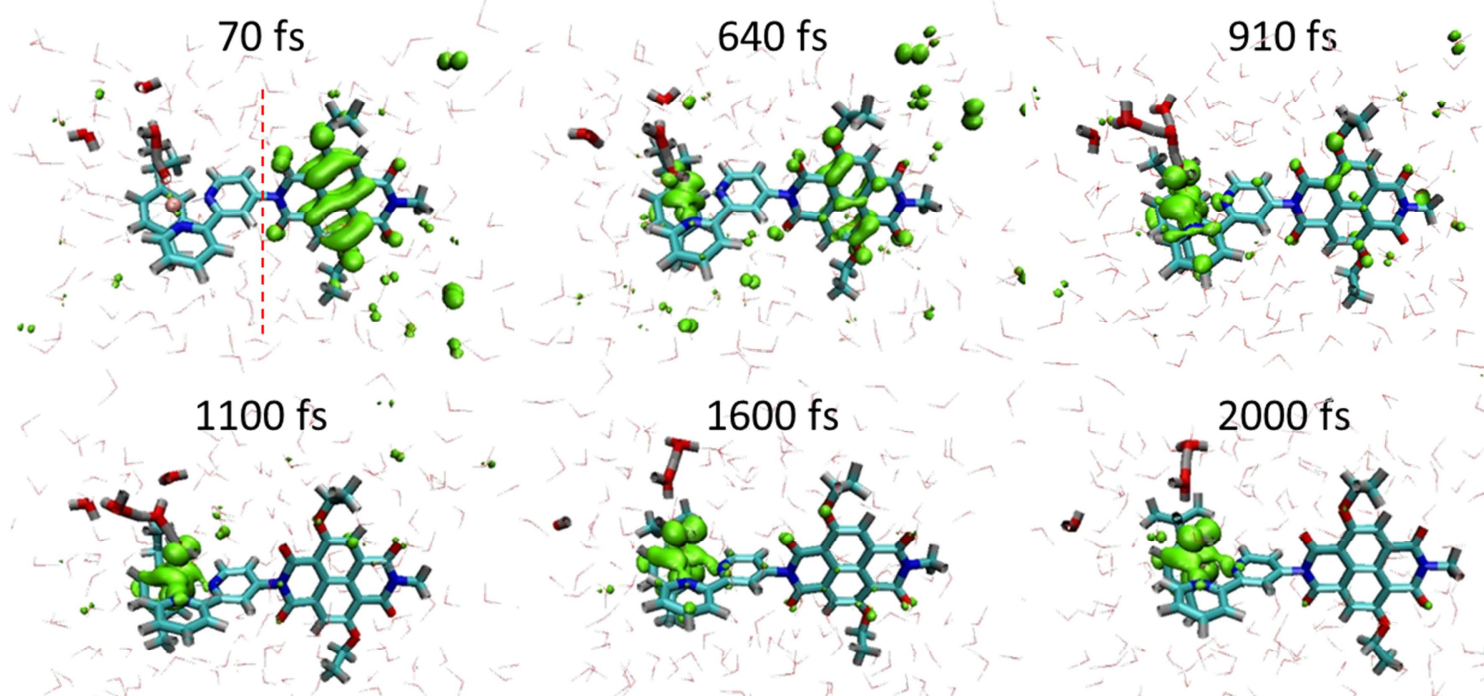

Figure 5. Spin density localization (in green) along the constrained MD trajectory shown in Figure 4. The labels refer to the time at which the snapshot has been taken along the collected trajectory of Figure 4. The spin density localized on a few water molecules is attributed to transient solvent polarization effects.

Further analysis of the constrained MD trajectories shows that the response of the solvent water molecules to the variation of the $\mathrm{H}(\mathrm{w} 1) \cdots \mathrm{O}(\mathrm{w} 2)$ distance does not only stabilize the spin density localization on the ruthenium catalyst, but also creates the conditions for the diffusion of one proton from the w1 molecule into the water bulk.

In order to characterize the proton diffusion, it is convenient to monitor how the coordination number of each oxygen atom of the solvent changes along the constrained MD trajectories. This is done by counting for each water molecule the number of protons $\left(\mathrm{N}_{\mathrm{H}}\right)$ within a sphere centered at the oxygen position. For the analysis presented in 
Figure 6, we consider a sphere of $1.2 \AA$ radius, previously identified as the distance for which the proton can be considered as shared between the oxygen of two water molecules (see Figure 3 ). The conclusions of this analysis are not affected by a variation of $\pm 10 \%$ of the sphere radius.

It is found that along the trajectory the majority of the solvent molecules retain the coordination number $\mathrm{N}_{\mathrm{H}}=\mathbf{2}$. In Figure 6a, we report the oxygen coordination number of the four water molecules whose $N_{H}$ value changes along the dynamical trajectory and thus play a major role in the proton diffusion. Figure $\mathbf{6 b}$ represents a snapshot extracted from the constrained MD trajectory, where these four water molecules are highlighted.

(a)

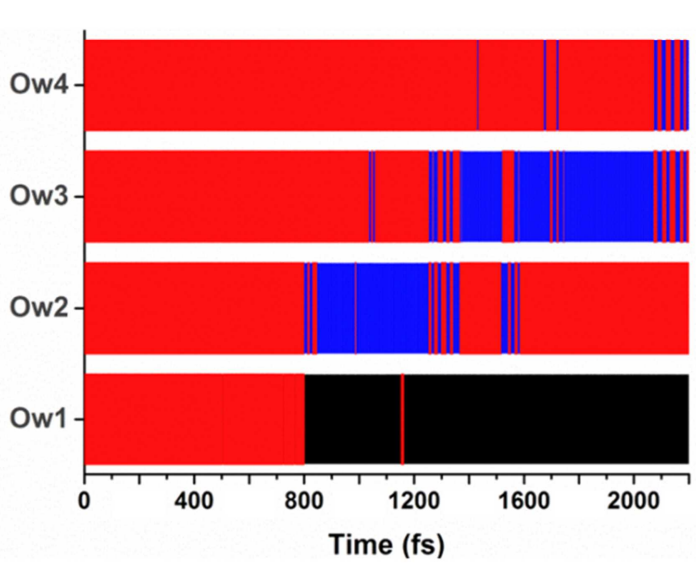

(b)

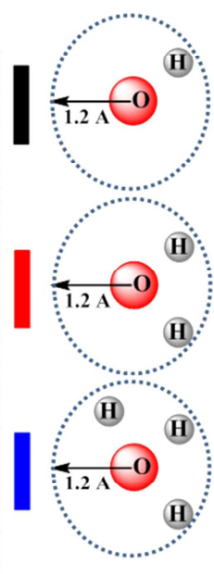

Ow3

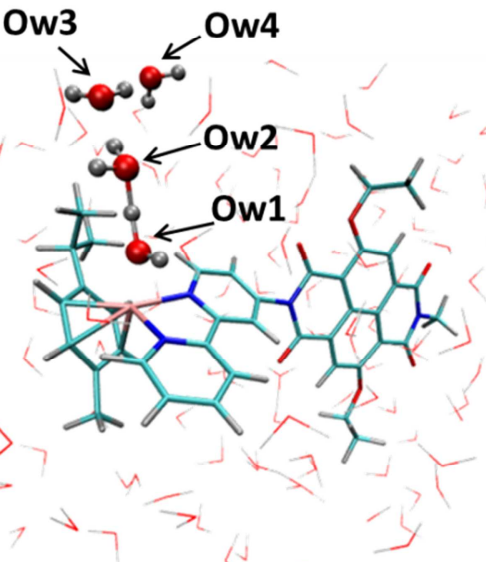

Figure 6. Path of proton diffusion from the $w 1$ molecule into the solvent bulk along the constrained MD trajectories. (a) The color scheme corresponds to the number of protons $\left(\mathrm{N}_{\mathrm{H}}\right)$ contained in a sphere of $1.2 \AA$ radius centered at each oxygen atom of the solvent: $\mathrm{N}_{H}=1$ (black); $\mathrm{N}_{H}=2$ (red); $\mathrm{N}_{\mathrm{H}}=3$ (blue). The oxygen atoms Ow1, Ow2, Ow3, and Ow4 highlighted in (b) are the only ones for which $\mathrm{N}_{\mathrm{H}}$ differs from 2 at any point along the trajectory. The variation of the $\mathrm{N}_{\mathrm{H}}$ indicates that the corresponding water molecules are actively involved in the proton diffusion from $\mathrm{w} 1$ to $\mathrm{w} 4$.

From the color pattern of Figure $\mathbf{6 a}$, it is possible to follow the path of proton diffusion from the Ru-coordinated water w1 to the bulk water molecule w4 (Figure 6b). Specifically, the localization of the excess proton is indicated by the blue regions associated to the oxygen coordination number $\mathrm{N}_{\mathrm{H}}=3$. It should be emphasized that while the proton jump from $\mathrm{w} 1$ to $\mathrm{w} 2$ is driven by the constraint applied to the reaction coordinate $\mathrm{H}(\mathrm{w} 1)-\mathrm{O}(\mathrm{w} 2)$, the subsequent proton transport steps from $\mathrm{w} 2$ to $\mathrm{w} 3$ and from w3 to w4 occur spontaneously following a Grotthuss type mechanism. The last part of the collected trajectory (Time>1800 fs) shows that even upon removal of the constraint, the proton further diffuses throughout the solvent via the same mechanism, generating mixing entropy that decreases the probability for back reaction.

These results provide strong evidence that the reduction of the oxidized antenna and the 
first catalytic water oxidation step represent a cooperative event proceeding via a concerted PCET process. The $\left[(\mathrm{cy}) \mathrm{Ru}^{\mathrm{III}} \mathrm{bpy}(\mathrm{HO})\right]^{2+}-\mathrm{NDI}_{1}$ product state reached for system 1b represents the first photoinduced catalytic intermediate in the Ru-catalyst water oxidation $\mathrm{cycle}^{40}$. The PCET nature of this process is also in agreement with the suggested catalytic mechanism ${ }^{40,78}$.

An estimate of the free energy profile along the reaction coordinate is extracted from the constrained dynamics ${ }^{77}$. The mean force values associated with the applied constraints, together with the polynomial fit used for this analysis, are reported in Figure SI4 in the supporting information. The obtained free energy profile for the PCET process reported in Figure 7 shows an activation energy barrier $\Delta \mathrm{G}^{*} \sim 1.7 \mathrm{kcal} \mathrm{mol}^{-1}$ ( $\sim 0.074 \mathrm{eV})$, which is equivalent to $\sim 3 k_{\mathrm{B}} T$ at room temperature.

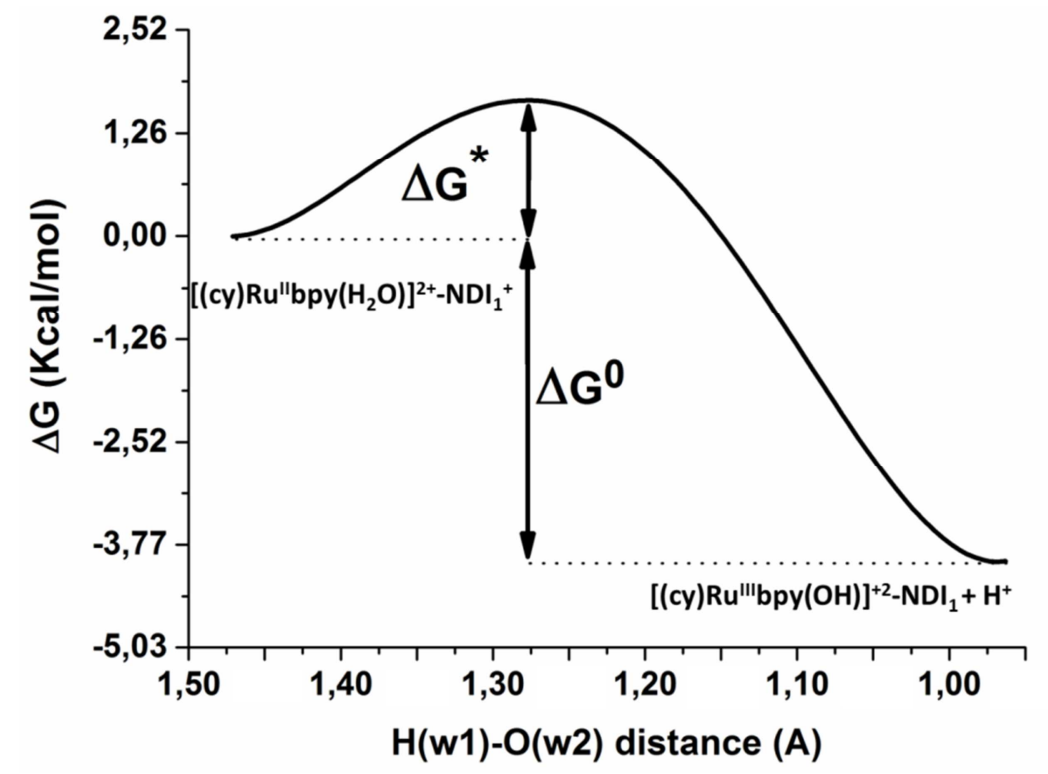

Figure 7 Free energy profile along the reaction coordinate $\mathrm{H}(\mathrm{w} 1)-\mathrm{O}(\mathrm{w} 2)$ for the first water oxidation catalytic step in system $\mathbf{1 b}^{+} . \Delta \mathrm{G}^{*}$ represents the height of the reaction energy barrier, while $\Delta G^{0}$ is the reaction driving force for the transition between the initial $\left[(\mathrm{cy}) \mathrm{Ru}^{\mathrm{II}} b p y\left(\mathrm{H}_{2} \mathrm{O}\right)\right]^{2+}-$ $\mathrm{NDI}_{1}^{+}$and the final $\left[(\mathrm{cy}) \mathrm{Ru}{ }^{\mathrm{III}} \mathrm{bpy}(\mathrm{OH})\right]^{2+}-\mathrm{NDI}_{1}+\mathrm{H}_{\text {solvated }}^{+}$state.

This low barrier suggests a very facile proton transfer step. However, from benchmark test studies for proton transfer energies, ${ }^{89}$ it can be inferred that the barrier estimated with local density functionals of the GGA type is about 3 to $3.5 \mathrm{kcal} \mathrm{mol}^{-1}$ lower than that calculated with highly correlated $a b$ initio methods. It should also be pointed out that since in our simulations the atoms are treated classically, the quantum effects associated with the proton motion are neglected. The inclusion of such effects is not expected to qualitatively change the nature of the PCET mechanism ${ }^{90}$, but it could effectively reduce this barrier and thus increase the proton diffusion rate. A rough estimate of the zero point energy correction for the analyzed catalytic step is found to be about $3 \mathrm{kcal} \mathrm{mol}^{-1}$, 
which is very similar to the functional related barrier underestimation. Therefore we can conclude that the functional related barrier underestimation and the quantum effects errors are in fact compensating each other to a large extent.

The reaction is found to be exothermic with the driving force $\Delta G^{0} \sim-4 \mathrm{kcal} \mathrm{mol}^{-1}(\sim 0.17$ $\mathrm{eV}$ ) (see Figure 7). The maximum of the free energy profile corresponds to a $\mathrm{H}(\mathrm{w} 1) \cdots \mathrm{O}(\mathrm{w} 2)$ distance of $1.28 \AA$. Interestingly, $\mathrm{H}(\mathrm{w} 1) \cdots \mathrm{O}(\mathrm{w} 2)$ distances comparable to $1.28 \AA$ are explored by the reactant during the unconstrained MD simulation (see Figure 3), although not resulting in the formation of a stable final product. Starting from the identified transition state $(\mathrm{H}(\mathrm{w} 1) \cdots \mathrm{O}(\mathrm{w} 2)=1.28 \AA)$, additional unconstrained simulations are performed with initial random velocity distributions corresponding to room temperature. Complete proton transfer between w1 and $\mathrm{w} 2(\mathrm{H}(\mathrm{w} 1)-\mathrm{O}(\mathrm{w} 2)<1.1 \AA)$ is observed several times in the same trajectory, although always followed by fast back proton transfer to $w 1$. These results indicate that the catalytic step (i) is thermodynamically favorable. However, the reaction rate is limited by the spontaneous formation of the proton channel identified through the constrained MD simulations, which allows for a fast proton diffusion from w1 into the solvent. An accurate estimate of the kinetics of proton channel formation can be obtained through advanced sampling techniques ${ }^{91-94}$, which is beyond the scope of this work.

\section{CONCLUSIONS}

This work presents a photoanode for solar water splitting involving a molecular catalyst ${ }^{6}$ and elucidates the dynamical details of the catalytic mechanism of the first water oxidation step. For the first time the proton and the electron dynamics is followed during the catalytic process, unambiguously showing the PCET nature of this reaction.

Semi-empirical quantum-classical simulations demonstrate that visible light photoexcitation of the $\mathrm{NDI}_{1}$ sensitizer induces ultrafast electron injection into the $\mathrm{TiO}_{2}$ semiconductor, activating the catalytic cycle. $A b$ initio MD simulations of the oxidized $\left[(\mathrm{cy}) \mathrm{Ru}^{\mathrm{II}} \text { bpy }\left(\mathrm{H}_{2} \mathrm{O}\right)\right]^{2+}-\mathrm{NDI}_{1}{ }^{+}$dyad $\left(\mathbf{1 b}^{+}\right)$in an explicit water solvent clearly show that the electron transfer between the catalyst and the oxidized antenna is concomitant with the diffusion of one proton from the metal-coordinated water to the solvent. These simulations also underline the primary role of the solvent in providing the reaction path through the formation of a hydrogen bonding network necessary for fast proton diffusion. The entropy increase due to the proton diffusion provides further stabilization of the catalytic intermediate $\left[(\mathrm{cy}) \mathrm{Ru}{ }^{\mathrm{III}} \mathrm{bpy}(\mathrm{OH})\right]^{2+}-\mathrm{NDI}_{1}$. This first catalytic step is exothermic and presents a very low activation barrier, suggesting that it can spontaneously proceed at room temperature.

The photochemical reaction simulations for our promising photoanode can be used as a 
starting point for extensive DS-PEC device optimization aiming at exploring the effect of different anchoring groups, ${ }^{95-97}$ increasing the driving force for the subsequent steps of the catalytic water photo-oxidation cycle, reducing the charge recombination rate, and accelerating the PCET step. This can be achieved through the introduction of ancillary chromophores with complementary absorption properties and redox potentials, ${ }^{42}$ bridge units with rectifying properties, ${ }^{59}$ and highly proton conductive channels. ${ }^{98}$

\section{ASSOCIATED CONTENT}

Supporting Information. Density of states for model 1a. Details of the AO/MO time propagation method. Comparison of spin density computed with different functionals. Spin density of first catalytic intermediate. Polynomial fit of mean force values. This material is available free of charge via the Internet at http://pubs.acs.org.

\section{AUTHOR INFORMATION}

\section{Corresponding Author}

*Email: f.buda@chem.leidenuniv.nl

\section{Notes}

The authors declare no competing financial interests.

\section{ACKNOWLEDGMENTS}

The use of supercomputer facilities was sponsored by NWO Physical Sciences, with financial support from the Netherlands Organization for Scientific Research (NWO). This research is financed by the NWO-ECHO project number 713.011.002.

\section{REFERENCES}

(1) Gust, D.; Moore, T. A.; Moore, A. L. Acc. Chem. Res. 2009, 42 (12), 1890-1898.

(2) Tachibana, Y.; Vayssieres, L.; Durrant, J. R. Nat Photon 2012, 6 (8), 511-518.

(3) Dau, H.; Limberg, C.; Reier, T.; Risch, M.; Roggan, S.; Strasser, P. ChemCatChem 2010, 2 (7), 724-761.

(4) Dau, H.; Zaharieva, I. Acc. Chem. Res. 2009, 42 (12), 1861-1870.

(5) Nocera, D. G. Acc. Chem. Res. 2012, 45 (5), 767-776.

(6) Berardi, S.; Drouet, S.; Francàs, L.; Gimbert-Suriñach, C.; Guttentag, M.; Richmond, C.; Stoll, T.; Llobet, A. Chem. Soc. Rev. 2014, 43 (22), 7501-7519.

(7) Hammarström, L.; Styring, S. Energy Environ. Sci. 2011, 4 (7), 2379-2388.

(8) Yu, Z.; Li, F.; Sun, L. Energy Environ. Sci. 2015, 8 (3), 760-775.

(9) Young, K. J.; Martini, L. A.; Milot, R. L.; Snoeberger III, R. C.; Batista, V. S.; Schmuttenmaer, C. A.; Crabtree, R. H.; Brudvig, G. W. Coordination Chemistry Reviews 2012, 256 (21-22), 2503-2520.

(10) Hamann, T. W. Nat Mater 2014, 13 (1), 3-4.

(11) Scholes, G. D.; Fleming, G. R.; Olaya-Castro, A.; van Grondelle, R. Nat Chem 2011, 3 (10), 763-774. 
(12) Tran, P. D.; Wong, L. H.; Barber, J.; Loo, J. S. C. Energy Environ. Sci. 2012, 5 (3), 5902-5918.

(13) Fujishima, A.; Honda, K. Nature 1972, 238 (5358), 37-38.

(14) Youngblood, W. J.; Lee, S.-H. A.; Kobayashi, Y.; Hernandez-Pagan, E. A.; Hoertz, P. G.; Moore, T. A.; Moore, A. L.; Gust, D.; Mallouk, T. E. J. Am. Chem. Soc. 2009, 131 (3), 926-927.

(15) Ashford, D. L.; Gish, M. K.; Vannucci, A. K.; Brennaman, M. K.; Templeton, J. L.; Papanikolas, J. M.; Meyer, T. J. Chem. Rev. 2015, 115 (23), 13006-13049.

(16) Zhao, Y.; Swierk, J. R.; Megiatto, J. D.; Sherman, B.; Youngblood, W. J.; Qin, D.; Lentz, D. M.; Moore, A. L.; Moore, T. A.; Gust, D.; Mallouk, T. E. PNAS 2012, 109 (39), 15612-15616.

(17) Maeda, K.; Teramura, K.; Lu, D.; Takata, T.; Saito, N.; Inoue, Y.; Domen, K. Nature 2006, 440 (7082), 295-295.

(18) Brillet, J.; Yum, J.-H.; Cornuz, M.; Hisatomi, T.; Solarska, R.; Augustynski, J.; Graetzel, M.; Sivula, K. Nat Photon 2012, 6 (12), 824-828.

(19) Reece, S. Y.; Hamel, J. A.; Sung, K.; Jarvi, T. D.; Esswein, A. J.; Pijpers, J. J. H.; Nocera, D. G. Science 2011, 334 (6056), 645-648.

(20) Higashi, M.; Domen, K.; Abe, R. J. Am. Chem. Soc. 2012, 134 (16), 6968-6971.

(21) Yang, J.; Wang, D.; Han, H.; Li, C. Acc. Chem. Res. 2013, 46 (8), 1900-1909.

(22) Zhang, J.; Wang, X. Angew. Chem. Int. Ed. 2015, 54 (25), 7230-7232.

(23) Blakemore, J. D.; Gray, H. B.; Winkler, J. R.; Müller, A. M. ACS Catal. 2013, 3 (11), 2497-2500.

(24) Ronconi, F.; Syrgiannis, Z.; Bonasera, A.; Prato, M.; Argazzi, R.; Caramori, S.; Cristino, V.; Bignozzi, C. A. J. Am. Chem. Soc. 2015, 137 (14), 4630-4633.

(25) Klepser, B. M.; Bartlett, B. M. J. Am. Chem. Soc. 2014, 136 (5), 1694-1697.

(26) Gao, Y.; Ding, X.; Liu, J.; Wang, L.; Lu, Z.; Li, L.; Sun, L. J. Am. Chem. Soc. 2013, 135 (11), 4219-4222.

(27) Duan, L.; Bozoglian, F.; Mandal, S.; Stewart, B.; Privalov, T.; Llobet, A.; Sun, L. Nat Chem 2012, 4 (5), 418-423.

(28) Kärkäs, M. D.; Verho, O.; Johnston, E. V.; Åkermark, B. Chem. Rev. 2014, 114 (24), 11863-12001.

(29) Swierk, J. R.; McCool, N. S.; Mallouk, T. E. J. Phys. Chem. C 2015.

(30) Ding, X.; Gao, Y.; Zhang, L.; Yu, Z.; Liu, J.; Sun, L. ACS Catal. 2014, 4 (7), 23472350.

(31) Li, H.; Li, F.; Zhang, B.; Zhou, X.; Yu, F.; Sun, L. J. Am. Chem. Soc. 2015, 137 (13), 4332-4335.

(32) Moore, G. F.; Blakemore, J. D.; Milot, R. L.; Hull, J. F.; Song, H.; Cai, L.; Schmuttenmaer, C. A.; Crabtree, R. H.; Brudvig, G. W. Energy Environ. Sci. 2011, 4 (7), 2389-2392.

(33) Pastore, M.; De Angelis, F. J. Am. Chem. Soc. 2015, 137 (17), 5798-5809.

(34) Vagnini, M. T.; Smeigh, A. L.; Blakemore, J. D.; Eaton, S. W.; Schley, N. D.; D’Souza, F.; Crabtree, R. H.; Brudvig, G. W.; Co, D. T.; Wasielewski, M. R. PNAS 2012, 109 (39), 15651-15656.

(35) Ji, Z.; He, M.; Huang, Z.; Ozkan, U.; Wu, Y. J. Am. Chem. Soc. 2013, 135 (32), 1169611699.

(36) Norris, M. R.; Concepcion, J. J.; Fang, Z.; Templeton, J. L.; Meyer, T. J. Angew. Chem. Int. Ed. 2013, 52 (51), 13580-13583.

(37) Ai, X.; Anderson, N. A.; Guo, J.; Lian, T. J. Phys. Chem. B 2005, 109 (15), 7088-7094. 
(38) Pastore, M.; Selloni, A.; Fantacci, S.; Angelis, F. D. In First Principles Approaches to Spectroscopic Properties of Complex Materials; Valentin, C. D., Botti, S., Cococcioni, M., Eds.; Topics in Current Chemistry; Springer Berlin Heidelberg, 2014; pp 1-45.

(39) Chen, J.; Li, Y.-F.; Sit, P.; Selloni, A. J. Am. Chem. Soc. 2013, 135 (50), 18774-18777.

(40) Vallés-Pardo, J. L.; Guijt, M. C.; Iannuzzi, M.; Joya, K. S.; de Groot, H. J. M.; Buda, F. ChemPhysChem 2012, 13 (1), 140-146.

(41) de Respinis, M.; Joya, K. S.; De Groot, H. J. M.; D’Souza, F.; Smith, W. A.; van de Krol, R.; Dam, B. J. Phys. Chem. C 2015, 119 (13), 7275-7281.

(42) Monti, A.; de Groot, H. J. M.; Buda, F. J. Phys. Chem. C 2014, 118 (29), 1560015609.

(43) Sakai, N.; Mareda, J.; Vauthey, E.; Matile, S. Chem. Commun. 2010, 46 (24), 42254237.

(44) Kishore, R. S. K.; Kel, O.; Banerji, N.; Emery, D.; Bollot, G.; Mareda, J.; GomezCasado, A.; Jonkheijm, P.; Huskens, J.; Maroni, P.; Borkovec, M.; Vauthey, E.; Sakai, N.; Matile, S. J. Am. Chem. Soc. 2009, 131 (31), 11106-11116.

(45) Yushchenko, O.; Villamaina, D.; Sakai, N.; Matile, S.; Vauthey, E. J. Phys. Chem. C 2015, 119 (27), 14999-15008.

(46) Sakai, N.; Bhosale, R.; Emery, D.; Mareda, J.; Matile, S. J. Am. Chem. Soc. 2010, 132 (20), 6923-6925.

(47) Avinash, M. B.; Swathi, K.; Narayan, K. S.; Govindaraju, T. ACS Appl. Mater. Interfaces 2016.

(48) Schroot, R.; Schlotthauer, T.; Schubert, U. S.; Jäger, M. Macromolecules 2016, 49 (6), 2112-2123.

(49) Bosma, W. B.; Fried, L. E.; Mukamel, S. The Journal of Chemical Physics 1993, 98 (6), 4413-4421.

(50) Auer, B.; Soudackov, A. V.; Hammes-Schiffer, S. J. Phys. Chem. B 2012, 116 (26), 7695-7708.

(51) Eisenmayer, T. J.; Buda, F. ChemPhysChem 2014, 15 (15), 3258-3263.

(52) Jackson, M. N.; Surendranath, Y. J. Am. Chem. Soc. 2016, 138 (9), 3228-3234.

(53) ADF: The ADF program for accurate density functional theory calculations of molecules http://www.scm.com/ADF/ (accessed Mar 7, 2013).

(54) te Velde, G.; Bickelhaupt, F. M.; Baerends, E. J.; Fonseca Guerra, C.; van Gisbergen, S. J. A.; Snijders, J. G.; Ziegler, T. Journal of Computational Chemistry 2001, 22 (9), 931-967.

(55) Swart, M.; Ehlers, A. W.; Lammertsma *, K. Molecular Physics 2004, 102 (23-24), 2467-2474.

(56) Hoffmann, R. The Journal of Chemical Physics 1963, 39 (6), 1397-1412.

(57) Ammeter, J. H.; Buergi, H. B.; Thibeault, J. C.; Hoffmann, R. J. Am. Chem. Soc. 1978, 100 (12), 3686-3692.

(58) Alvarez, S. Table of parameters for Extended Hückel Calculations 1995, Universitait de Barcelona.

(59) Monti, A.; Negre, C. F. A.; Batista, V. S.; Rego, L. G. C.; de Groot, H. J. M.; Buda, F. J. Phys. Chem. Lett. 2015, 6 (12), 2393-2398.

(60) Hoff, D. A.; Silva, R.; Rego, L. G. C. J. Phys. Chem. C 2011, 115 (31), 15617-15626.

(61) da Silva, R.; Hoff, D. A.; Rego, L. G. C. Journal of Physics: Condensed Matter 2015, 27 (13), 134206.

(62) Hoff, D. A.; da Silva, R.; Rego, L. G. C. J. Phys. Chem. C 2012, 116 (40), $21169-$ 21178.

(63) Abuabara, S. G.; Rego, L. G. C.; Batista, V. S. J. Am. Chem. Soc. 2005, 127 (51), 18234-18242. 
(64) Rego, L. G. C.; Hames, B. C.; Mazon, K. T.; Joswig, J.-O. J. Phys. Chem. C 2014, 118 (1), 126-134.

(65) CPMD, http://www.cpmd.org/, Copyright IBM Corp 1990-2008, Copyright MPI fürFestkörperforschung Stuttgart 1997-2001.

(66) Lin, I.-C.; Coutinho-Neto, M. D.; Felsenheimer, C.; von Lilienfeld, O. A.; Tavernelli, I.; Rothlisberger, U. Phys. Rev. B 2007, 75 (20), 205131.

(67) Troullier, N.; Martins, J. L. Phys. Rev. B 1991, 43 (3), 1993-2006.

(68) Klamt, A.; Jonas, V. The Journal of Chemical Physics 1996, 105 (22), 9972-9981.

(69) Klamt, A. J. Phys. Chem. 1995, 99 (7), 2224-2235.

(70) Carvalho, A. T. P.; Swart, M. J. Chem. Inf. Model. 2014, 54 (2), 613-620.

(71) Groenhof, A. R.; Ehlers, A. W.; Lammertsma, K. J. Am. Chem. Soc. 2007, 129 (19), 6204-6209.

(72) Conradie, J.; Ghosh, A. J. Chem. Theory Comput. 2007, 3 (3), 689-702.

(73) Stephens, P. J.; Devlin, F. J.; Chabalowski, C. F.; Frisch, M. J. J. Phys. Chem. 1994, 98 (45), 11623-11627.

(74) Ma, C.; Piccinin, S.; Fabris, S. ACS Catal. 2012, 2 (7), 1500-1506.

(75) Otter, W. K. den; Briels, W. J. The Journal of Chemical Physics 1998, 109 (11), 41394146.

(76) Sprik, M.; Ciccotti, G. The Journal of Chemical Physics 1998, 109 (18), 7737-7744.

(77) Ciccotti, G.; Ferrario, M. Molecular Simulation 2004, 30 (11-1), 787-793.

(78) Joya, K. S.; Vallés-Pardo, J. L.; Joya, Y. F.; Eisenmayer, T.; Thomas, B.; Buda, F.; de Groot, H. J. M. ChemPlusChem 2013, 78 (1), 35-47.

(79) Kanan, M. W.; Nocera, D. G. Science 2008, 321 (5892), 1072-1075.

(80) Maggio, E.; Martsinovich, N.; Troisi, A. Angew. Chem. Int. Ed. 2013, 52 (3), 973-975.

(81) Ding, W.; Negre, C. F. A.; Vogt, L.; Batista, V. S. J. Chem. Theory Comput. 2014, 10 (8), 3393-3400.

(82) Hassanali, A.; Giberti, F.; Cuny, J.; Kühne, T. D.; Parrinello, M. PNAS 2013, 110 (34), 13723-13728.

(83) Marx, D.; Chandra, A.; Tuckerman, M. E. Chem. Rev. 2010, 110 (4), 2174-2216.

(84) Agmon, N. Chemical Physics Letters 1995, 244 (5-6), 456-462.

(85) Codorniu-Hernández, E.; Kusalik, P. G. PNAS 2013, 110 (34), 13697-13698.

(86) Liang, R.; Li, H.; Swanson, J. M. J.; Voth, G. A. PNAS 2014, 111 (26), 9396-9401.

(87) de Grotthuss, C. J. T. Biochimica et Biophysica Acta (BBA) - Bioenergetics 2006, 1757 (8), 871-875.

(88) Cheng, J.; Sulpizi, M.; VandeVondele, J.; Sprik, M. ChemCatChem 2012, 4 (5), 636640.

(89) Nachimuthu, S.; Gao, J.; Truhlar, D. G. Chemical Physics 2012, 400, 8-12.

(90) Tuckerman, M. E.; Marx, D.; Klein, M. L.; Parrinello, M. Science 1997, 275 (5301), 817-820.

(91) Pietrucci, F.; Saitta, A. M. Proc. Natl. Acad. Sci. U.S.A. 2015, 112 (49), 15030-15035.

(92) Bolhuis, P. G.; Chandler, D.; Dellago, C.; Geissler, P. L. Annual Review of Physical Chemistry 2002, 53 (1), 291-318.

(93) Laio, A.; Parrinello, M. PNAS 2002, 99 (20), 12562-12566.

(94) Geissler, P. L.; Dellago, C.; Chandler, D.; Hutter, J.; Parrinello, M. Science 2001, 291 (5511), 2121-2124.

(95) Mathew, S.; Yella, A.; Gao, P.; Humphry-Baker, R.; Curchod, B. F. E.; Ashari-Astani, N.; Tavernelli, I.; Rothlisberger, U.; Nazeeruddin, M. K.; Grätzel, M. Nat Chem 2014, 6 (3), 242-247.

(96) Ambrosio, F.; Martsinovich, N.; Troisi, A. J. Phys. Chem. Lett. 2012, 3 (11), 15311535 . 
(97) Zhang, L.; Cole, J. M. ACS Applied Materials \& Interfaces 2015, 7, 3427-3455.

(98) Matsuki, Y.; Iwamoto, M.; Mita, K.; Shigemi, K.; Matsunaga, S.; Oiki, S. J. Am. Chem. Soc. 2016. 
Table of Contents and Abstract Graphics

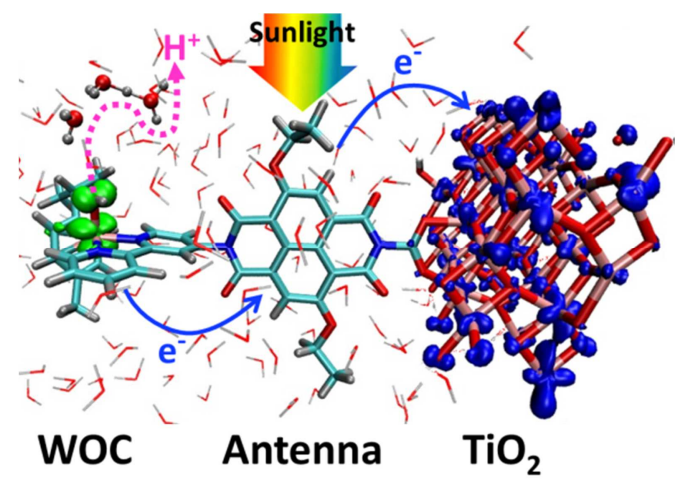

